\title{
Sterilization of Surgical Tools: Removing Bacterial Endospores with a Combination of Povidone-iodine, Chlorhexidine Gluconate, Ethanol, and Methanol
}

\author{
Tweij-Thu-Alfeqar Razzaq ${ }^{1}$ (D), Al-Jameel-Dheyaa Shnan²* (D) and Alaasam-Bassim \\ Mohammed $\mathrm{Ali}^{3}$
}

${ }^{1}$ Department of Basic Sciences, Faculty of Dentistry, University of Kufa, Al-Najaf, Iraq. ${ }^{2}$ Department of Pathology, Faculty of Medicine, Jabir Ibn Hayyan Medical University, Al-Najaf, Iraq. ${ }^{3}$ Department of Oral and Maxillofacial Surgery, Faculty of Dentistry, University of Kufa, Al-Najaf, Iraq.

\begin{abstract}
A combination of chemicals including povidone-iodine, chlorhexidine gluconate, ethanol, and methanol were used to remove Bacillus thuringiensis endospores from surgical tools. This study included two steps: the first one was conducted using four increasing concentrations of each compound. The best chemical concentration for a single agent was $7.5 \%$ povidone-iodine with only 3 colony-forming units (CFU) produced after treatment, 5\% chlorhexidine treatment resulted in $12 \mathrm{CFU}, 70 \%$ ethanol yielded 9 CFU, and $\mathbf{9 0 \%}$ methanol resulted in $20 \mathrm{CFU}$. The second step included the following (v/v) combinations: $90 \%$ methanol $+70 \%$ ethanol, $90 \%$ methanol $+5 \%$ chlorhexidine, and $7.5 \%$ iodine $+70 \%$ ethanol + $\mathbf{5 \%}$ chlorhexidine. The latter combination resulted in $\mathbf{0}$ CFU and therefore, sterilization was achieved. The combination $7.5 \%$ iodine $+5 \%$ chlorhexidine resulted in 1 CFU, $7.5 \%$ iodine $+90 \%$ methanol in 4 CFU, $7.5 \%$ iodine $+70 \%$ ethanol yielded 6 CFU, and the combination $5 \%$ chlorhexidine $+90 \%$ methanol resulted in $9 \mathrm{CFU}$. The control treatment yielded about $300 \mathrm{CFU}$. To confirm results, a vegetative growth of Pseudomonas aeruginosa, Klebsiella pneumoniae, Staphylococcus aureus, and Enterococcus faecalis were subjected to the same disinfection procedure and no bacterial growth were obtained for all the disinfectant combinations. Sterilization is defined as the process aimed at destroying or eliminating all kind of microbes and it is indispensable in health care settings.
\end{abstract}

Keywords: Endospore, Bacillus thuringiensis, Surgical tools, disinfectants, Full sterilization.

*Correspondence: dheyaa.shnan@jmu.edu.iq; +9647800933298

(Received: 15 September 2019; accepted: 17 December 2019)

Citation: Tweij-Thu-Alfeqar Razzaq, Al-Jameel-Dheyaa Shnan and Alaasam-Bassim Mohammed Ali, Sterilization of Surgical Tools: Removing Bacterial Endospores with a Combination of Povidone-iodine, Chlorhexidine Gluconate, Ethanol, and Methanol, J Pure Appl Microbiol., 2019; 13(4): 2499-2506 https://doi.org/10.22207/JPAM.13.4.65

(C) The Author(s) 2019. Open Access. This article is distributed under the terms of the Creative Commons Attribution 4.0 International License which permits unrestricted use, sharing, distribution, and reproduction in any medium, provided you give appropriate credit to the original author(s) and the source, provide a link to the Creative Commons license, and indicate if changes were made. 


\section{INTRODUCTION}

Sterilization can be conducted using chemical or physical methods such as dry heat, steam with pressure, hydrogen peroxide, and chemical solutions. Disinfectants are chemicals applied to non-living objects and able to kill or eliminate pathogenic microbes with the exception of bacterial spores. Inanimate objects used in health care are mostly disinfected by wet pasteurization or liquid chemicals ${ }^{1}$.

\section{Instrument classification}

To determine the amount of chemical agent and the type of disinfection method required for surgical and other medical instruments that are reusable, the instruments are classified in three types: critical, semi-critical, and noncritical. Critical instruments are those that are used on sterile tissue, including blood vessels, implants, endoscopic biopsy forceps, laparoscopes, and arthroscopes. Semi-critical instruments are in contact with mucous membranes or nonhealthy skin, but are not used on sterile tissues. Cystoscopes, gastrointestinal endoscopes, gronchoscopes, anesthesia, vaginal probes, and respiratory therapy equipment are examples of this type of instruments. Noncritical tools are those in contact only with intact skin, such as blood pressure cuffs, tourniquets, linens, general use equipment, furnishings, and environmental surfaces ${ }^{2}$.

The efficacy of any sterilization and disinfection method depends on the following three basic aspects. First, to achieve an effective destruction of living organisms. Second, the sterilizing processes and tools must be validated and suitable in design and procedure to accomplish a good combination of temperature and sterilant agent to be effective on microorganisms. Devices undergoing a disinfection process must be cleaned to reduce bio burden to further confirm the effectiveness of the disinfection process. Third, there must be enough contact between the sterilant and all surfaces and cracks of the device to be sterilized ${ }^{3}$. There are many methods used to sterilize and disinfect instruments such as steam, heat, chemicals, and others chemical methods using compounds with antiseptic or antimicrobial properties.

Chlorhexidine gluconate (CHG)

Chlorhexidine gluconate is active against gram-negative and gram-positive bacteria including aerobes and anaerobes, yeasts, and fungi. CHG is a synthetic antimicrobial drug widely used as a broad-spectrum antiseptic in clinical and veterinary medicine ${ }^{4}$. The mechanism of action is through the interaction of the positive charge on the CHG molecule with negatively charged phosphate groups on the microbial cell wall resulting in a change in the osmotic equilibrium of the cell. The increase in the cell wall permeability allows the CHG molecule to penetrate the microbe and facilitate the release of cytoplasmic material ${ }^{5,6}$. Sterilization and disinfection are necessary to prevent the dissemination of infectious pathogens to patients and staff. The current study is an attempt to obtain a better sterilizing method.

\section{Povidone-iodine}

Povidone-iodine is produced by the binding of free iodine to the solubilizing agent polyvinyl-pyrrolidone (PVP). This process is conducted to decrease the degree of toxicity of iodine as it exerts its antimicrobial effect when released from the PVP molecule ${ }^{7}$. Once released, iodine is toxic to microbes because it irreversibly associates with residues of tyrosine in the protein structure, interacts through the formation of hydrogen bonds with several amino acids and nucleic acids, oxidizes sulfhydryl groups, and reacts with lipid unsaturation ${ }^{8}$. Povidone-iodine is a broad-spectrum antimicrobial solution effective against a variety of pathogens including Staphylococcus aureus 9 . In addition to its antibacterial activity, it is also effective against fungi, viruses, protozoa, and some bacterial spores ${ }^{10}$. PVP-iodine has rapid in vitro activity (it is bactericidal within 15-20 s) and the duration of the effect on the skin has been reported to be 12-14 $\mathrm{h}$ due to a phenomenon called back-diffusion ${ }^{11,12}$. Compared with antibiotics, there is little chance for bacteria to develop resistance to PVP-iodine because of the multiple cellular targets ${ }^{13}$.

\section{Alcohols}

Alcohols are colorless solutions having one or more of functionally active hydroxyl groups ${ }^{14}$. Alcohols are classified as bacteriostatics or bactericidals against vegetative bacteria; they also act as a fungicidals, tuberculocidals, and virucidals but they do not destroy bacterial spores ${ }^{15}$. Methyl alcohol (methanol) has the weakest bactericidal action among all alcohols and thus, it is seldom 
used in healthcare ${ }^{16}$. Ethanol exhibits rapid broad-spectrum antimicrobial activity, and as a dehydrating agent causes cell membrane damage, rapid denaturalization of proteins concomitantly interfering with metabolism, and cell lysis ${ }^{17}$. Ethyl alcohol is used to disinfect surgical instruments, facemasks, thermometers, and for skin antisepsis before injections ${ }^{13}$. A major advantage of alcohol aqueous solutions is that they do not leave any residue on treated items ${ }^{18}$.

\section{Aim of the study}

This study was aimed at introducing new combinations of different concentrations of povidone-iodine, $\mathrm{CHG}$, ethanol, and methanol to achieve sterilization of surgical tools and equipment.

The novelty of this research is the use of four different concentrations of each agent in addition to the combination of two or more agents. This approach allows the determination of the best combination that provides the greatest protection against infective microorganisms especially considering the high amount of new resistant microorganisms. The best combination may be used in the sterilization of instruments and tools in surgery and other medical devices that are in direct contact with patients, such as thermometers, laparoscopes, and other tools.

\section{MATERIAL AND METHODS Study design}

This study included two steps, the first one conducted using four serial concentrations of each of the following compounds: povidone-iodine, $\mathrm{CHG}$, ethanol, and methanol (Mast Diagnostic, City, USA) to disinfect or sterilize different surgical tools contaminated with Bacillus thuringiensis endospores and then with a vegetative growth of Pseudomonas aeruginosa, Klebsiella pneumoniae, Staphylococcus aureus, and Enterococcus faecalis. Preparation of sterilizing/disinfecting agents

The sterilants/disinfectants used in the current study are standard solutions of povidone iodine (10\%), CHG $(5 \%)$, ethanol $(100 \%)$, and methanol (100\%). The chemicals were used to prepare various concentrations of fresh solutions diluting them with distilled water ${ }^{19}$ (Table 1).

Sterilization and contamination of surgical tools

All the surgical tools included in this study were pre-sterilized in an autoclave at $121^{\circ} \mathrm{C}$ for 30 minutes and under 15 pounds of pressure for standardization. Spore-forming Bacillus thuringiensis bacterial isolates were obtained from the College of Agriculture, Kufa University and were characterized to the species level using morphological and biochemical tests ${ }^{20,21}$. The isolate was confirmed as $B$. thuringiensis through the amplification of the $16 \mathrm{~S}$ rRNA gene with $\mathrm{PCR}^{22}$. To obtain a homogenous spore suspension, a tube containing $5 \mathrm{~mL}$ of saline was inoculated with a 1 $\mathrm{mL}$ of a spore suspension and then incubated for three days at $55^{\circ} \mathrm{C}$. Further, pre-sterilized surgical tools were contaminated with $B$. thuringiensis for 5 minutes, subjected to the sterilant solution for 5 minutes, and then washed with saline. The suspension was vortexed and $0.1 \mathrm{~mL}$ of the washing solution was seeded onto $8 \mathrm{~cm}$-diameter Petri dishes containing nutrient agar (Himedia, City, India). Petri dishes were incubated for 24 hours at $37^{\circ} \mathrm{C}$ and the number of well-isolated colonies counted. The control group consisted of contaminated surgical tools subjected to the same procedure without using any sterilizing solutions.

The best sterilizing concentrations of single agents were combined as indicated in Table 2, and a second round of procedures were conducted as described above but using the mixtures.

For confirmation purposes, the combination of disinfectants was used to sterilize vegetative growth of pathogenic bacteria that were obtained from the Microbiology laboratory of the College of Dentistry, Kufa University. Bacteria used were the following: P. aeruginosa, K. pneumoniae, S. aureus, and E. faecalis. All bacteria were cultured and a suspension of the bacterial growth was prepared on nutrient broth (Himedia, City, India). The same above procedures described for endospores have been repeated with vegetative bacteria.

\section{Statistical analysis}

The statistical analysis was conducted with the Statistical Package for Social Science (SPSS) version 25 and analysis of variance was performed using one-way ANOVA and Post-Hoc LSD multiple comparison tests. Results were considered significant at $\mathrm{p} \leq 0.05$.

\section{RESULTS AND DISCUSSION}

Any invasive medical procedure requires 
surgical tools or equipment and therefore, infection may arise without effective sterilization. The use of standard sterilizing solutions may be ineffective because of bacterial resistance and the presence of bacterial endospores poses and additional challenge. Sterilization aims at achieving complete destruction or elimination of all type of microbes and it can be performed through autoclaving or incineration; however, for medical instruments that need to be reused the two procedures may not be effective ${ }^{23}$.

This study included the testing of various concentrations of different disinfectant solutions and a combination of them with the goal of killing bacterial endospores to achieve sterilization of surgical tools and equipment. The reason why $B$. thuringiensis endospores were used in this study is that it is a non-pathogenic spore-forming bacterium that is heat resistant and easy to germinate and form colonies ${ }^{24}$.

Antibacterial effect of povidone-iodine

Povidone-iodine was used at four different concentrations $2.5 \%, 5 \%, 7.5 \%$, and $10 \%$.

Table 1. Concentration of sterilizing agents

\begin{tabular}{lcccc}
\hline \multicolumn{3}{l}{ SolutionConcentration (\%) } & & \\
\hline Povidone iodine & 10 & 7.5 & 5 & 2.5 \\
Chlorhexidine & 5 & 4 & 3 & 2 \\
gluconate & & & & \\
Ethanol & 100 & 90 & 80 & 70 \\
Methanol & 100 & 90 & 80 & 70 \\
\hline
\end{tabular}

The best concentration with a significantly higher capacity to control endospore contamination was $7.5 \%$, which resulted in the appearance of $3 \mathrm{CFU}$. A $10 \%$ concentration yielded 5 CFU, then the $5 \%$ concentration resulted in $14 \mathrm{CFU}$, and the less effective concentration was $2.5 \%$ with 21 CFU. All povidone-iodine concentrations and the result of their effects are depicted in Fig. 1.

The best povidone-iodine effect was obtained with the $7.5 \%$ concentration yielding only $3 \mathrm{CFU}$, this may be explained considering that iodine makes direct contact with living cells and iodinate the lipids components of the plasma membrane ${ }^{25}$. Higher chemical concentrations show lower activity probably because of their

Table 2. combination of sterilizing agents

\begin{tabular}{lc}
\hline Solution & $\begin{array}{c}\text { Combined } \\
\text { concen. }(\mathrm{v} / \mathrm{v})^{*}\end{array}$ \\
\hline lodine + Chlorhexidine & $7.5+5$ \\
lodine + Ethanol & $7.5+70$ \\
lodine + Methanol & $7.5+90$ \\
Chlorhexidine + Ethanol & $5+70$ \\
Chlorhexidine + Methanol & $5+90$ \\
Ethanol + Methanol & $70+90$ \\
lodine + Chlorhexidine & $7.5+5+70$ \\
+ Ethanol & \\
\hline
\end{tabular}

*Prepared by mixing equal volume of each agent of certain concentration example iodine $7.5 \%$ with Chlorhexidine $5 \%$.

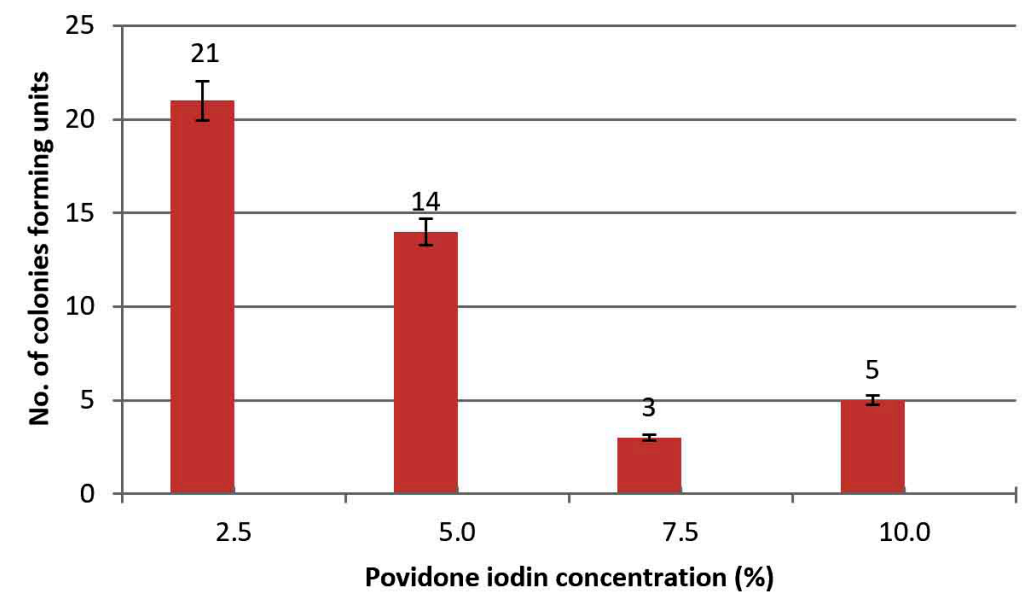

Fig. 1. Number of colonies forming units (CFU) on agar plate resulted from growth of $B$. thuringiensis spores after spreads $0.1 \mathrm{ml}$ of spore suspension from surgical tools treated by povidone iodine solution. 
lower oxidation ability due to competition for the site of attachment and penetration within the walls of the endospore. Lower concentrations such as $5 \%$ and $2.5 \%$ resulted in lower antibacterial activity because of the low concentration of the active compound. The growth of Bacillus subtilis endospores was inhibited with a one-minute exposure to $0.5-1 \%$ of iodine in a $70 \%$ ethanol solution $^{26}$.

\section{Antibacterial effect of CHG}

Four concentrations of $\mathrm{CHG}$ solutions were used: $2 \%, 3 \%, 4 \%$, and $5 \%$. The best concentration that showed significant ability to control bacterial endospores was $5 \%$ yielding 12 CFU. The $4 \%$ concentration resulted in $14 \mathrm{CFU}$, the $3 \%$ concentration yielded $38 \mathrm{CFU}$, and for the $2 \%$ concentration the number of CFU was 75.

The higher $\mathrm{CHG}$ efficacy corresponded to the $5 \%$ concentration and the effect might be due to positively charged CHG salts binding to negatively charged compounds on the bacterial cell wall making it more prone to leaking and for the cell to burst, and because of the blockage of the potassium channel ${ }^{27}$. Other concentrations

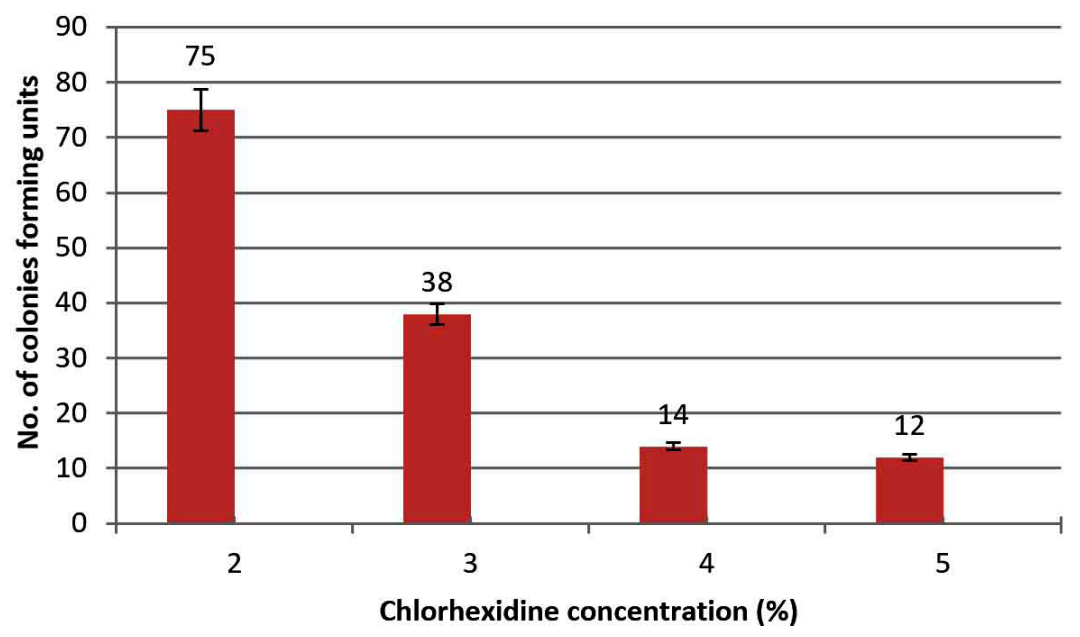

$\operatorname{LSD}(P \leq 0.05)=30.679$

Fig. 2. Number of colonies forming units (CFU) on agar plate resulted from growth of $B$. thuringiensis spores after spreads $0.1 \mathrm{ml}$ of spore suspension from surgical tools treated with Chlorhexidine solution.

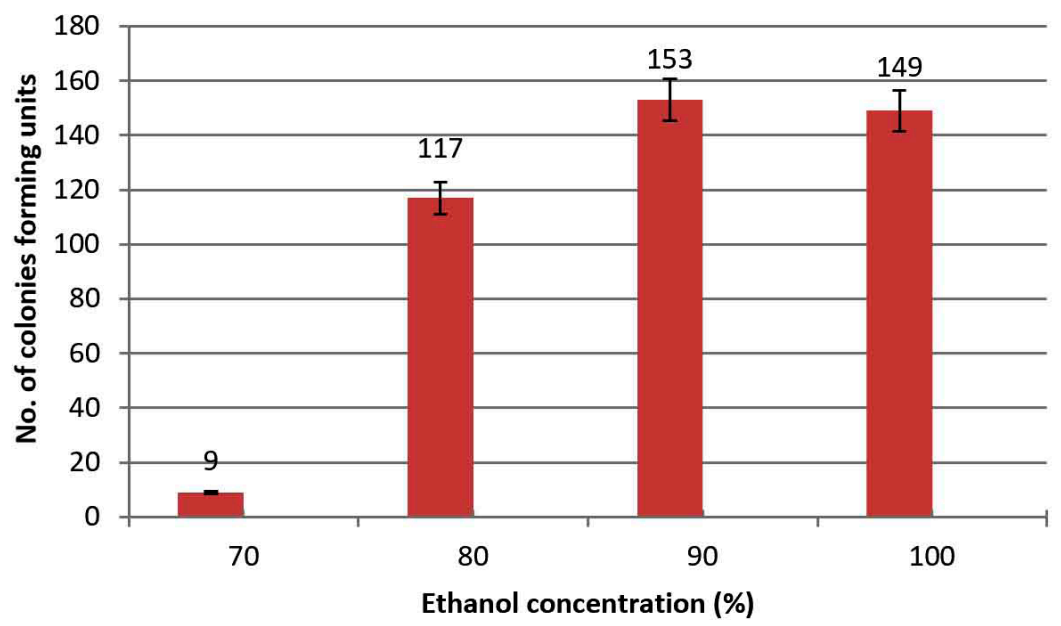

$\operatorname{LSD}(P \leq 0.05)=50.037$

Fig. 3. Number of colonies forming units (CFU) on agar plate resulted from growth of $B$. thuringiensis spores after spreads $0.1 \mathrm{ml}$ of spore suspension from surgical tools treated with Ethanol solution. 
produce a lower effect because of the low availability of $\mathrm{CHG}$.

\section{Antibacterial effect of ethanol}

Ethanol is usually used as a disinfectant agent. We prepared $70 \%, 80 \%, 90 \%$, and $100 \%$ solutions. The $70 \%$ concentration showed significant activity compared to other concentrations since only 9 CFU were produced compared to $117 \mathrm{CFU}$ for the $80 \%$ concentration. For $90 \%$ and $100 \%$ ethanol concentrations the number of CFI was 153 and 149, respectively.

Ethanol is more effective at the $70 \%$ concentration yielding $9 \mathrm{CFU}$; this significant growth inhibition is due to its ability to coagulate and denature proteins ${ }^{28}$. The hydroxyl group in ethanol attaches to microbial proteins through hydrogen bonds causing destruction of protein structures. Concentrations of $80 \%, 90 \%$, and $100 \%$ show lower activity compared to the $70 \%$ concentration because ethanol cannot penetrate the microbe ${ }^{29}$. Suchomel et al. used three ethanol concentrations, $75 \%, 85 \%, 95 \%$ for three minutes and reported that the $75 \%$ and $95 \%$ ethanol concentrations were more effective than the $85 \%$ concentration. These authors also compared the effect of ethanol with the one of $60 \%$ propanol.

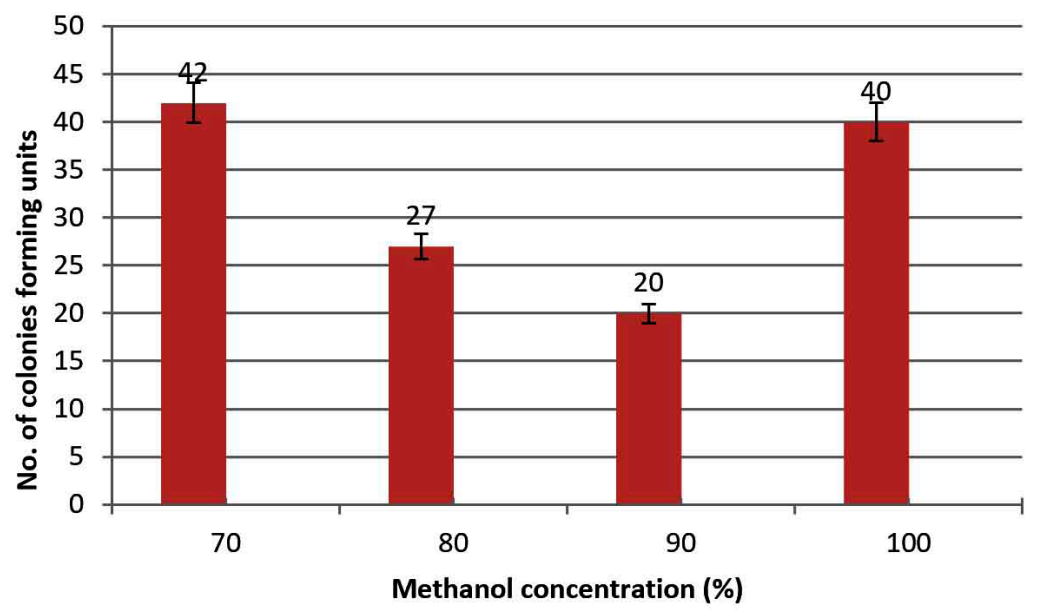

$\operatorname{LSD}(P \leq 0.05)=15.668$

Fig. 4. Number of colonies forming units (CFU) on agar plate resulted from growth of $B$. thuringiensis spores after spreads $0.1 \mathrm{ml}$ of spore suspension from surgical tools treated with Methanol solution.

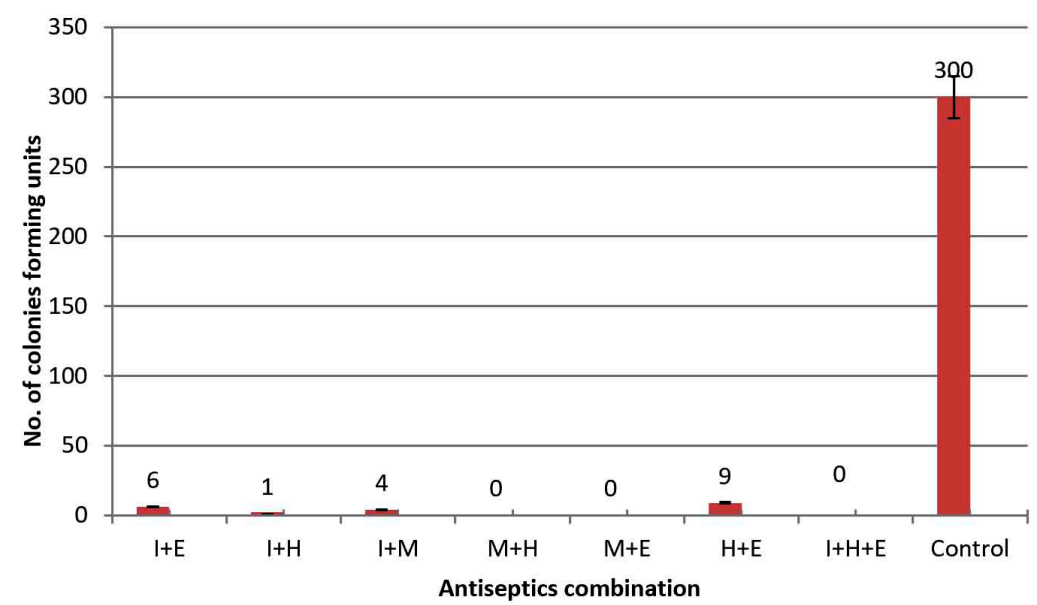

$\operatorname{LSD}(P \leq 0.05)=6.176$

Fig. 5. Number of colonies forming units (CFU) on agar plate resulted from growth of $B$. thuringiensis spores after spreads $0.1 \mathrm{ml}$ of spore suspension from surgical tools sterilized by combination of different sterilizing solutions.l, povidone iodine; E, Ethanol; $\mathrm{H}$, Chlorhexidine; M, Methanol 
Propanol was more effective than any of the ethanol concentrations ${ }^{30}$.

Antibacterial effect of methanol

Methanol is rarely used as a sterilizing solution; but in this study, we used it as a single agent to compare it with others chemicals tested and to study the effect of the combination of methanol with other reagents. A $90 \%$ concentration treatment yielded 20 CFU, whereas $80 \%, 70 \%$, and $100 \%$ concentrations resulted in 27,42 , and 40 CFU, respectively.

Methanol was less effective in killing bacterial spores compared to other solutions. The best concentration to inhibit bacterial growth was $90 \%$ and this is probably because this concentration prevents endospore germination without killing it. A similar behavior was reported for methanol-treated fungal spores ${ }^{31}$. Methanol has also been used as a solvent for the inactivation of Bacillus pumilus spores on heat sensitive devices $^{32}$. Furthermore, ice-cold methanol was used in the precipitation of polyhydroxybutyrate from endospore-forming Bacillus megaterium demonstrating its ability to destroy endospores ${ }^{33}$. Antibacterial effect of the disinfectant combinations

The second group of experiments was conducted combining the disinfectants used in the first group of experiments at their most effective concentrations (Table 2). In the control treatment where no sterilizing solutions were used on surgical tools, 300 CFU resulted from the germination of bacterial endospores. The following $\mathrm{v} / \mathrm{v}$ combinations resulted in complete sterilization (0 CFU): $90 \%$ methanol + $5 \%$ chlorhexidine, $90 \%$ methanol $+70 \%$ ethanol, and $75 \%$ iodine $+5 \%$ chlorhexidine $+70 \%$ ethanol. Other chemical combinations were effective in controlling microbial growth but sterilization was not achieved, such is the case of $7.5 \%$ iodine + $5 \%$ chlorhexidine that yielded only $1 \mathrm{CFU}, 7.5 \%$ iodine $+90 \%$ methanol that yielded 4 CFU, $7.5 \%$ iodine $+70 \%$ ethanol $70 \%$ resulted in $6 \mathrm{CFU}$, and $5 \%$ chlorhexidine $+90 \%$ methanol which led to 9 CFU.

There was no vegetative growth of $P$. aeruginosa, K. pneumoniae, S. aureus and $E$. faecalis for the above combination of disinfectants.

Several of the combinations tested were effective preventing germination of bacterial endospores. The combination of CHG with ethyl alcohol and cetyl lactate produces a very high topical antimicrobial effect with and immediate, persistent, and residual bactericidal activity; this also relates to the low temperature used in the manufacturing process for the production of $\mathrm{CHG}$ salts in alcohol-based formulations ${ }^{34}$. The results of our study did not agree with the results of CHAKRABORTY et al. were endospores of $B$. subtilis were not inhibited with a $70 \%$ aqueous ethanol solution after the exposure of spores for 24 hours at $4^{\circ} \mathrm{C}, 25^{\circ} \mathrm{C}$, and $37^{\circ} \mathrm{C}^{26}$.

\section{ACKNOWLEDGMENTS}

All the diagnosis of bacterial isolates supported by the microbiology lab, faculty of dentistry, Kufa University.

\section{CONFLICTS OF INTEREST}

The authors declare that there is no conflict of interest.

\section{FUNDING}

None.

\section{AUTHORS' CONTRIBUTION}

All authors listed have made a substantial, direct and intellectual contribution to the work, and approved it for publication.

\section{DATA AVAILABILITY}

All datasets generated or analyzed during this study are included in the manuscript.

\section{ETHICS STATEMENT}

This article does not contain any studies with human participants or animals performed by any of the authors.

\section{REFERENCES}

1. CDC Guidelines for Disinfection and Sterilization in Healthcare Facilities, https://www.cdc.gov/ Accessed 6 June, 2019.

2. Seballos RJ, Walsh AL, Mehta AC. Clinical evaluation of a liquid chemical sterilization system for the flexible bronchoscope. Journal of Bronchology \& Interventional Pulmonology. 1995 Jul 1;2(3):192-199.

3. Seavey R. High-level disinfection, sterilization, and antisepsis: current issues in reprocessing medical and surgical instruments. American journal of infection control. 2013 May 1; 41(5):S111-117.

4. Emilson CG. Susceptibility of various microorganisms 
to chlorhexidine. European journal of oral sciences. 1977 Aug; 85(4):255-265.

5. Gomes BP, Souza SF, Ferraz CC, Teixeira FB, Zaia AA, Valdrighi L, Souza-Filho FJ. Effectiveness of $2 \%$ chlorhexidine gel and calcium hydroxide against Enterococcus faecalis in bovine root dentine in vitro. International Endodontic Journal. 2003 Apr 1; 36(4):267-275.

6. Gomes BP, Sato E, Ferraz CC, Teixeira FB, Zaia $A A$, Souza-Filho FJ. Evaluation of time required for recontamination of coronally sealed canals medicated with calcium hydroxide and chlorhexidine. International Endodontic Journal. 2003 Sep; 36(9):604609.

7. Dedo DD, Alonso WA, Ogura JH. Povidone-iodine: an adjunct in the treatmen of wound infections, dehiscences, and fistulas in head and neck surgery. Transactions. Section on Otolaryngology. American Academy of Ophthalmology and Otolaryngology. 1977;84(1):68-74.

8. Ellman GL. Tissue sulfhydryl groups. Archives of biochemistry and biophysics. 1959 May 1;82(1):70-77.

9. Watt BE, Proudfoot AT, Vale JA. Hydrogen peroxide poisoning. Toxicological reviews. 2004 Mar 1;23(1):5157.

10. Russell AD. Bacterial spores and chemical sporicidal agents. Clinical microbiology reviews. $1990 \mathrm{Apr}$ 1;3(2):99-119.

11. McLure AR, Gordon J. In-vitro evaluation of povidoneiodine and chlorhexidine against methicillin-resistant Staphylococcus aureus. Journal of hospital infection. 1992 Aug 1;21(4):291-299.

12. Gottardi W. The uptake and release of molecular iodine by the skin: chemical and bactericidal evidence of residual effects caused by povidone-iodine preparations. Journal of Hospital Infection. 1995 Jan 1;29(1):9-18.

13. Klossner BL, Widmer HR, Frey F. Nondevelopment of resistance by bacteria during hospital use of povidonelodine. Dermatology. 1997;195(Suppl. 2):10-13.

14. Prescott,L.M.; Harley,J.P.; Klein,A.K.;(2005); Microbiology; pp134-146, 6th Edition; McGraw Hill.

15. Rutala WA, Weber DJ. Disinfectants used for environmental disinfection and new room decontamination technology. American journal of infection control. 2013 May 1;41(5):S36-41.

16. Tilley FW, Schaffer JM. Relation between the chemical constitution and germicidal activity of the monohydric alcohols and phenols. Journal of bacteriology. 1926 Nov; 12(5):303.

17. Rubin $\mathrm{E}$, Rottenberg $\mathrm{H}$. Ethanol-induced injury and adaptation in biological membranes. In Federation proceedings 1982 Jun (Vol. 41, No. 8, pp. 2465-2471).

18. Zaman MH, Ferdouse S, Mahbub S, Hossain MM. Sterilization Pattern of Dental Clinics in Rangpur City. Bangladesh Journal of Dental Research \& Education. 2013 Oct 14;3(2):1-4.

19. Royal Pharmaceutical Society of Great Britain(2011) British national formulary 61.pp ;742-744 Royal pharmaceutical society.

20. Petras SF, Casida LE. Survival of Bacillus thuringiensis spores in soil. Appl. Environ. Microbiol. 1985 Dec 1;50(6):1496-1501.

21. Lin CC, Casida LE. GELRITE as a gelling agent in media for the growth of thermophilic microorganisms. Appl. Environ. Microbiol. 1984 Feb 1;47(2):427-429.

22. Rajashekhar M, Kalia VK. Biochemical and molecular characterization of Bacillus spp. isolated from insects. Journal of Entomology and Zoology Studies. 2017;5(5):581-8.

23. Hugo WB. A brief history of heat and chemical preservation and disinfection. Journal of Applied Bacteriology. $1991 \mathrm{Jul} ; 71(1): 9-18$.

24. Al-Jamell D, Al-Nasrawi S, Al Quraine N, Aljdaimi A. The effectiveness of three different methods for sterilization of the endodontic files (an In vitro study). 2224-7181. 2014 Dec 31;27:1-6.

25. Strand CL, Wajsbort RR, Sturmann K. Effect of lodophor vs iodine tincture skin preparation on blood culture contamination rate. JAMA. 1993 Feb 24;269(8):10046.

26. Chakraborty S, Hasan Mz, Chakma K, Harun-Or-Rashid An, Gomes D. Inactivation Of Bacterial Vegetative Cells And Endospores With Some Chemical Disinfectants J. Bioi. Sci. 2007;16(2): 109-115.

27. Russell $A D$, Day MJ. Antibacterial activity of chlorhexidine. Journal of Hospital Infection. 1993 Dec 1;25(4):229-238.

28. McDonnell G. General mechanism of action. In: McDonnel GE. 2017. Antisepsis, Disinfection, and Sterilization. Pp. 255-269, 2nd ed. ASM Press, Washington DC.

29. Yoo JH. Review of disinfection and sterilization-Back to the basics. Infection \& chemotherapy. 2018 Jun 1;50(2):101-109.

30. Suchomel M, Rotter M. Ethanol in pre-surgical hand rubs: concentration and duration of application for achieving European Norm EN 12791. Journal of Hospital Infection. 2011 Mar 1;77(3):263-266

31. Rao CY, Brain JD, Burge HA. Reduction of Pulmonary Toxicity of Stachybotrys chartarum Spores by Methanol Extraction of Mycotoxins. Appl. Environ. Microbiol. $2000 \mathrm{Jul}$ 1;66(7):2817-2821.

32. Shieh E, Paszczynski A, Wai CM, Lang $Q$, Crawford RL. Sterilization of Bacillus pumilus spores using supercritical fluid carbon dioxide containing various modifier solutions. Journal of Microbiological Methods. 2009 Mar 1;76(3):247-52.

33. Lopez JA, Naranjo JM, Higuita JC, Cubitto MA, Cardona CA, Villar MA. Biosynthesis of PHB from a new isolated Bacillus megaterium strain: outlook on future developments with endospore forming bacteria. Biotechnology and bioprocess engineering. $2012 \mathrm{Apr}$ 1;17(2):250-8.

34. Osborne DW, Kirchner F, inventors; Calgon Vestal Inc, assignee. Topical antimicrobial cleanser containing chlorhexidine gluconate and alcohol. United States patent US 5,776,430. $1998 \mathrm{Jul} 7$. 